\title{
Odontogenic Cervico-Facial Cellulitis at the University Hospital of Brazzaville: About 431 Cases
}

\author{
Eboungabeka Trigo Edith Rose Marcelle ${ }^{1,2}$, Dibansa Olivier ${ }^{1}$, Lekesse Chanelle $^{1}$ \\ ${ }^{1}$ Department of Stomatology and Maxillofacial Surgery of the University Hospital of Brazzaville, Brazzaville, Congo \\ ${ }^{2}$ Health Sciences Faculty, Marien NGOUABI University, Brazzaville, Congo \\ Email: eboungatrigo@yahoo.fr
}

How to cite this paper: Eboungabeka Trigo, E.R.M., Dibansa, O. and Lekesse, C. (2020) Odontogenic Cervico-Facial Cellulitis at the University Hospital of Brazzaville: About 431 Cases. Open Journal of Stomatology, 10, 19-27.

https://doi.org/10.4236/ojst.2020.102003

Received: December 26, 2019

Accepted: February 3, 2020

Published: February 6, 2020

Copyright $\odot 2020$ by author(s) and Scientific Research Publishing Inc. This work is licensed under the Creative Commons Attribution International License (CC BY 4.0).

http://creativecommons.org/licenses/by/4.0/

\begin{abstract}
Context and Objective: Cellulitis is potentially serious polymicrobial infections that can be life-threatening for the patient. They are clearly increasing in our service. It is with the aim of determining the hospital frequency of cellulitis of dental origin epidemiological profile, describing the clinical types, the therapeutic modalities and evaluating the results obtained. Subjects and Methods: This is a retrospective descriptive study on the files of 431 hospitalized patients, between January 2010 and December 2018 in the department of stomatology and maxillofacial surgery of the University Hospital of Brazzaville (Congo). The studied parameters: The frequency, the age, the gender, the origin, the consultation average time, the contributing factors, the entrance gate, the seat, the paraclinical assessment, the therapeutic modalities and the evolution. Results: Cervico-facial cellulitis accounted for $32.8 \%$ of hospitalizations. The average age was $32.8 \pm 1.98$ years, ranges from 3 to 93 years. The predominance was male with 241 cases, or $55.9 \% .64 .73 \%$ of patients came from CHUB emergencies. The mandibular seat was dominant with $77.72 \%$ of cases. The average consultation time was 6 days. As a contributing factor, we found the consumption of nonsteroidal anti-inflammatory drugs (NSAIDs). Tooth decay was the most common etiology $92.5 \%$. Antibiotic therapy and surgery had a good evolution in $96.8 \%$ of cases. The mortality rate was $3.3 \%$. Conclusion: odontogenic cervicofacial cellulitis remains common in daily practice. Patient care should focus on the preventive component integrating patient awareness of oral health.
\end{abstract}

\section{Keywords}

Cervico-Facial Cellulitis, Epidemiology, Clinical, Treatment 


\section{Introduction}

Cellulite is a polymicrobial condition with a predominance of anaerobes and commensal germs of the oral flora [1] [2].

Cervico-facial cellulitis is a complication of dental and periodontal infections, it constitutes a real emergency in daily dental practice [3]. It is of dental origin in $56 \%$ to $95 \%$ of cases [4] [5] [6]. Tooth decay accounts for more than $90 \%$ of cases in Africa [7]. The main causative teeth are the mandibular molars [8]. It is an infection that has an extensive tendency and may be life-threatening because of the progressive speed and severity of the complications. Despite this seriousness, no study has been conducted to determine the incidence of odontogenic cellulitis in the department of stomatology and maxillofacial surgery of the University Hospital of Brazzaville (rep. of Congo). NGOUONI et al. found a prevalence of cellulite of $34 \%$ in their series of diffuse cellulites carried out in 2005 [9]. In this perspective, we realized this study which aims to determine the hospital frequency of dental cellulitis, describe the clinical types and evaluate the results obtained.

\section{Subjects and Methods}

This is a retrospective descriptive study concerning 431 patient files treated in the department of stomatology and maxillofacial surgery of the University Hospital of Brazzaville (rep. of Congo). Patients were treated for cervicofacial cellulitis of dental origin between January 2010 and December 2018. The files collected included all patients with clinical signs of an acute cervicofacial infection of a dental origin requiring hospitalization and whose records were exploitable. Data were collected from the hospital registry and medical files. The variables studied were frequency, age, gender, origin, location, consulting period, contributing factors, entrance gate, reason for consultation, paraclinical assessment, therapeutic modalities and treatment, evolution. Patients with a non-dental condition were excluded: tumoral, salivary, traumatic, ganglionic and those that did not require hospitalization. Data were processed with MS Excel 2013 software.

The study had the ethical clearance of the institutional ethics committee. The collection of data was done taking into consideration the global rules of ethics relating to the respect of confidentiality and the protection of data specific to patients.

\section{Results}

We recorded 431 cases of cervicofacial cellulitis out of a total of 1315 hospitalized in the department during the study period, representing $32.8 \%$ of all hospitalizations with a rate of about 45 cases/year.

The annual rate of cervicofacial cellulitis cases is reported in Figure 1.

The mean age of the patients was $32.8 \pm 1.98$ years with extremes of 3 and 93 years. The most affected age group is $16-30$ years old. We found a male predominance with 241 cases or $55.9 \%$, the sex ratio was 1.3 . 
The distribution of cases of cervicofacial cellulitis by age and sex is reported in Figure 2.

Inpatients came from CHUB emergencies in 279 cases (64.73\%), 144 cases (33.41\%) in the outpatient unit and 8 cases (1.68\%) directly from the home.

The average consultation time was 6 days, with extremes of 2 and 14 days. As a contributing factor, we recorded the consumption of nonsteroidal anti-inflammatory drugs taken in self-medication in $72.4 \%$ of cases (Figure 3 ).

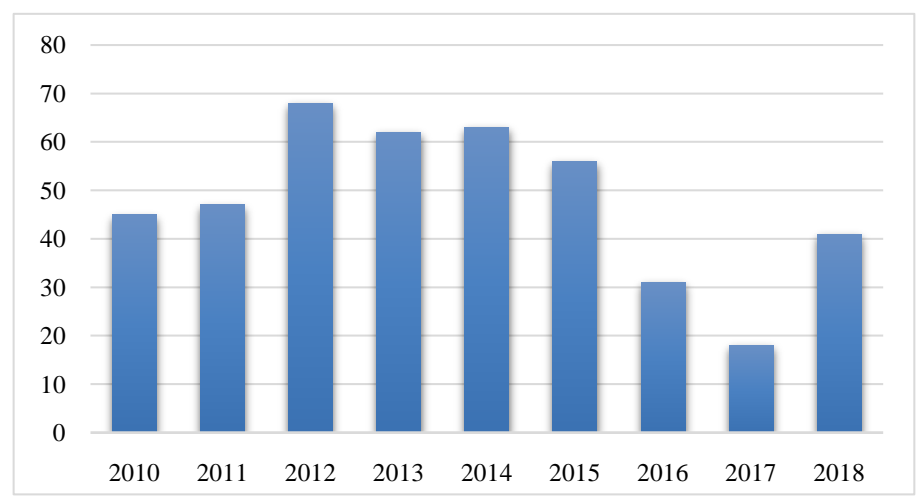

Figure 1. Annual frequency of cellulitis cases.

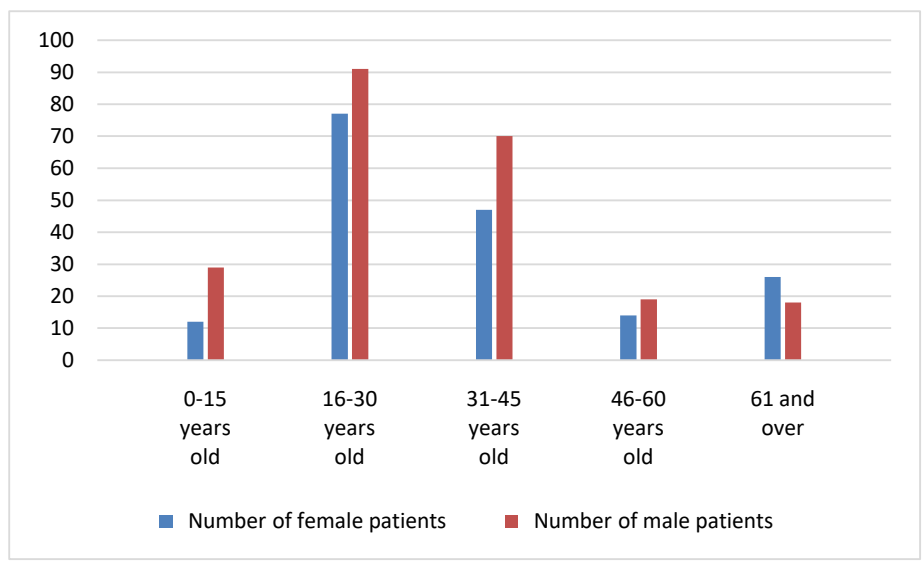

Figure 2. Patients distribution by age and gender.

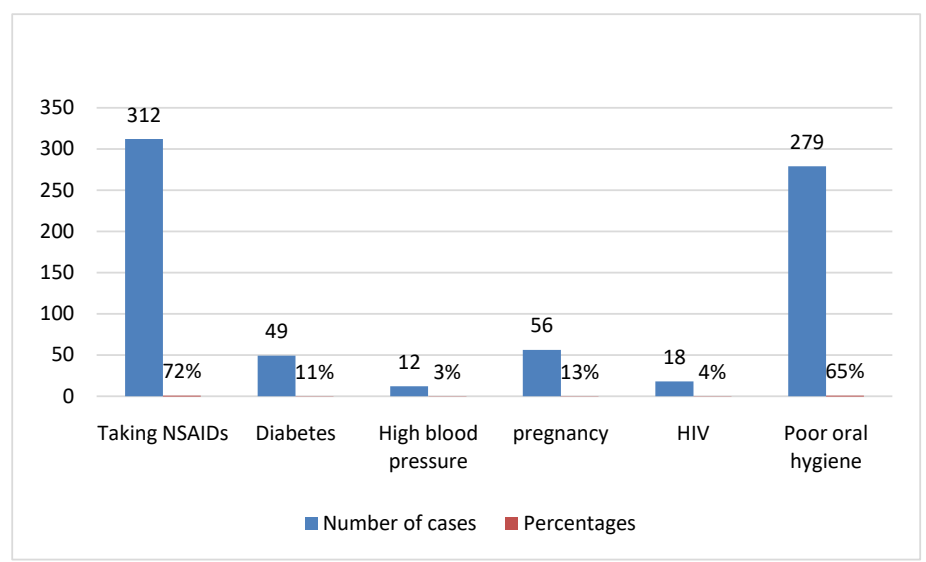

Figure 3. Cases distribution according to the contributing factors. 
Dental caries was the most frequent entry point in 398 cases, or $92.5 \%$. The distribution of cases by etiology is reported in Table 1 .

319 patients (74\%) had suppurative cellulitis, $12 \%$ had serious cellulitis and $14 \%$ had gangrenous cellulitis. The mandibular region found $77.72 \%$ of cases against $22.27 \%$ cases for the maxilla.

The main functional sign that led patients to consult was inflammatory facial swelling in $90 \%$ of cases. The other functional signs were trismus 310 cases, dysphagia 112 cases, dyspnea 5 cases and cutaneous necrosis 18 cases. 101 patients were febrile or $23.43 \%$ of the cases and 37 had an impairment of the general state is $8.58 \%$.

Bacteriological examination has not been systematically performed. Only 12 patients or $2.8 \%$ were able to do so, they were polymicrobial infections incriminating streptococci, staphylococci and anaerobic germs.

Standard radiological examinations in orthopantomogram or maxillary incidence were performed in $98 \%$ of patients, showing the different dental and periodontal causes.

All patients received parenteral bi or triple therapy (Table 2).

112 patients were put on steroids: solu-medrol 80 to $120 \mathrm{mg}$ once a day, for a duration of 3 to 5 days. The main analgesic molecule used was paracetamol.

Surgical drainage was performed on three 312 patients, consisting of a mechanical knife incision with evacuation of pus, debridement of necrotic tissue, and heavy washing with dakin and hydrogen peroxide, with the placement of a drainage slide.

The duration of hospitalization ranged from 2 to 30 days with an average of 12 days.

The evolution was favorable with a high cure rate of $96.7 \%$. The mortality rate was $3.3 \%$ in patients who developed severe septicemia.

Table 1. Patients distribution by etiology.

\begin{tabular}{ccc}
\hline Etiology & Number of patients & Percentage \\
\hline Tooth decay & 398 & $92.43 \%$ \\
Periodontal disease & 4 & $0.93 \%$ \\
Dental care & 8 & $1.86 \%$ \\
Extraction & 15 & $3.48 \%$ \\
Pericoronitis & 6 & $1.39 \%$ \\
\hline
\end{tabular}

Table 2. First-line medical treatment.

\begin{tabular}{lcc}
\hline \multicolumn{1}{c}{ ATB Protocol } & Number of patients & Percentage (\%) \\
\hline $\begin{array}{l}\text { Amoxicillin-Clavulanic acid } 3 \mathrm{~g} / \mathrm{j}+ \\
\text { Metronidazole } 1.5 \mathrm{~g} / \mathrm{j}\end{array}$ & 319 & 74.01 \\
$\begin{array}{l}\text { Amoxicillin } 3 \mathrm{~g} / \mathrm{j}+\text { Metronidazole } 1.5 \mathrm{~g} / \mathrm{j} \\
\begin{array}{l}\text { Amoxicillin-Clavulanic acid + ciprofloxacin } 2 \mathrm{~g} / \mathrm{j} \\
+ \text { Metronidazole } 1.5 \mathrm{~g} / \mathrm{j}\end{array}\end{array}$ & 74 & 17.17 \\
\hline
\end{tabular}




\section{Discussion}

Cellulitis was the first reason of hospitalization in our department, with a hospital prevalence of $32.8 \%$ and an annual rate of about 45 cases, compared with results of Rouadi 43 cases [10]. In 2012, Assouan et al. reported an annual incidence of 57.7 cases [11]. This digit did not reflect the actual number of cellulitis cases, as many where treated as outpatients, others were referred to O. R. L. department or refused to be hospitalized for lack of funds. The high incidence of odontogenic cellulitis in our context was mainly due to neglect of oral health and declining socioeconomic level.

The average age in our series was $32.8 \pm 1.98$ years, while HOUNKPE [12] reported 18 years old. In other African studies, this age ranges were 28 to 31 years [10] [13]. In France, it was about 51 years [14]. These different studies show that cellulitis can affect patients of any age.

A male predominance was found in our study, which was almost unanimous of the authors [5] [11] [13] [15] [16]. KPEMISSI reported a female predominance in 1995 [17]. Women who are more health and appearance conscious would consult early [18].

Several studies conducted around the world, particularly in Africa, confirm the high rate of cellulitis in patients from disadvantaged backgrounds [5] [6] [16] [17] [18]. In northern countries, cellulitis has become rare [19] [20].

Many authors emphasize the enabling role of the field, in particular diabetes [10] [11] [13] [17] [21]. In our series NSAIDs represent the first contributing factors with 312 cases or $72.4 \%$. Benariba F. and Kpemissi E. recovered respectively $82.35 \%$ and $75 \%$ of patients [17] [22]. The use of NSAIDs is considered by all authors as one of the predominant contributing factors in the occurrence of cervicofacial cellulitis [6] [17] [18] [22]. In fact, NSAIDs mask the signs of inflammation and lower immunity, leading to an increase in infection [11]. Among the comorbidities associated, diabetes accounted for only 49 cases or $11.4 \%$ of our series, contrary to the results mentioned by Diallo et al., who describe in their cohort the dramatic evolution of cervico-facial cellulitis on this field debilitated with high mortality [16].

The entrance gate is the starting point for the dissemination of the germ. Dental involvement is found in $100 \%$ of the patients in our series, Keita and Bengondo, found the same entrance gate in the proportions of $90 \%$ and $76 \%$ respectively [5] [6]. Tooth decay is the most common cause, particularly in Africa where it can be found in more than 90\% of cases [6] [15] [16] [18]. The carious pathology is often neglected, hence the high rate in the occurrence of cervico-facial cellulitis. Contrary to our results, in France, Mateo et al. noted a prevalence of pharyngeal involvement in $50 \%$ of cases, followed by dental involvement in $20 \%$ of cases [19].

The mandibular molars are the most incriminated in the appearance of cellulitis and our results are comparable with the literature [6] [7]. The susceptibility of the mandibular molars to caries and the ease of diffusion of the infection into 
the cellulo-fatty tissues of the perimandibular regions explain the frequency of cellulitis at the lower floor of the face.

The low frequency of maxillary point cellulitis is due to the depth of the vestibule and its lack of cellulo-fatty tissue, mainly to the palate where the adhering fibro mucosa limits the proliferation of the infection and only leads to periosteum abscess [23].

The patients consulted when a painful cervicofacial inflammatory tumefaction appeared with an aesthetic prejudice. It was also the reason for consultation most frequently found in the literature [14] [18]. Usually, we found the association to a trismus and an odynophagia. Often General signs were also present: fever, chills and sweating [18].

The majority of patients in our series consulted between the 4th and the 14th day of evolution, which justifies the high rate of suppurated cellulitis found with $74 \%$ of cases. They usually consulted late after failure of self-medication or traditional therapy.

The germs involved are variable; it is most often saprophytic germs of the oral cavity. The predominance of anaerobic germs is unanimous [17] [24]. Despite the formal indication of the literature data, we were able to perform only $12 \%$ or $2.8 \%$ of bacteriological samples because of the problems of indigence of most of our patients.

Panoramic dental radiography is essential for odontogenic cellulitis. Chest $\mathrm{x}$-rays can be used to diagnose complications, especially if there is a spread of infection to the mediastinum. Computed tomography is a considerable diagnostic, topographical and prognostic contribution and allows an adequate therapeutic choice but it's very high-cost limits access to this examination [17] [20]. In our series, all patients underwent a panoramic dental x-ray or maxillary parade.

Our therapeutic approach is based on antibiotic therapy associated with elimination of etiology. The absence of bacteriology has forced us to adopt a probabilistic attitude for most patients in our series. The medical treatment consisted of a combination therapy consisting of amoxicillin-metronidazole, amoxicillin-clavulanic acid-metronidazole or amoxicillin-clavulanic acid-ciprofloxacinmetronidazole, based on data from the literature [11] [16] [24]. This therapeutic choice is based on the fact that all cellulites are polymicrobial. The synergy of these associations is recognized as active on streptococci and anaerobes, very often incriminated in the presence of areas of necrosis and fetidity encountered intraoperatively [25]. Short-term corticosteroid therapy lasting 3 to 5 days was instituted to reduce obstructive edema in $78 \%$ of cases. The influence of corticosteroids on morbidity or the risk of mediastinal extension has been suspected, but never demonstrated [21].

The surgical treatment consisted of draining the suppurated collections and debridement of all necrotic tissues under local or general anesthesia, with local care and multi-day dressings, as well as the management of the entrance point as in the literature [5] [12] [16] [22]. We found that in patients treated with general anesthesia with good drainage, symptom improvement was achieved within 48 
to 72 hours. Patients treated under local anesthesia the amendment was much slower due to insufficient drainage, which forced us to do the dressings multiple times and for consequences the increase in the length of stay and hospital costs.

The average duration of hospitalization was 12 days, with extremes of 3 and 30 days.

The evolution was favorable, with a high cure rate of $96.7 \%$. The various published series find a mortality rate in the order of $7 \%$ to $40 \%$ [5] [16] [25]. In our series, the mortality rate was $3.3 \%$ in patients with severe septicemia charts.

\section{Conclusion}

Odontogenic cervicofacial cellulitis is a potentially serious and increasing infection in our department. Most of these patients are young, healthy and with a generally good dental condition. Mainly of dental origin, they are aggravated by taking anti-inflammatory drugs and inadequate initial management. The management of these infections is expensive and the socio-professional and economic repercussions are heavy hence the interest of an effective and targeted prevention, through oral prevention measures, proper management of carious pathology and knowledge of possible complications. Hospital mortality can be reduced with the condition of early diagnosis and immediate management.

\section{Conflicts of Interest}

The authors declare no conflicts of interest regarding the publication of this paper.

\section{References}

[1] Kouassi, Y.M., Janvier, B., Boulaich, E.E. and Kzardri, E.M. (2007) Cervico-Facial Dermohypodermitis Revealing of Cutaneous Lymphomas. Revue de Stomatologie et de Chirurgie Maxillo- Faciale, 108, 228-230.

https://doi.org/10.1016/j.stomax.2006.11.005

[2] Beech, N., Goh, R. and Lynham, A. (2014) Management of Dental Infections by Medical Practitioners. Australian Family Physician, 43, 289-291.

[3] Gaillard, A. (1989) Cellulitis and Fistula of Dental Origin. In: Encyclopedia, Medicine, Surgery, Dentistry and Stmatology, 22-033A10 Scientific Expansion, Paris.

[4] Loppin, M., Adamski, H., Larrègue, M., Frame, B., Godey, B. and Chevrant-Breton, J. (2006) Cervico-Facial Ulcerations Related to a Dental Infective Focus in Children. Archives de Pédiatrie, 13, 249-251. https://doi.org/10.1016/j.arcped.2005.10.018

[5] Doumbi, A.K., Diallo, M., Timbo, S.K. and Mohamed, A. (2008) Cervical Cellulitis in Sub-Sahelian Hospital Environment. A Forgotten Pathology? Mali Case. Black African Medicine, 55, 8-9.

[6] Bengondo, C.H., Ngoa, S., Onana, J., Ewo, C., Ewo, C. and Bengono, G. (2006) Carious Morbidity in the Odontostomatology Departments of Yaoundé. Tropical Odontostomatology, 113, 22-26.

[7] Karengera, D. (1991) Perimaxillary Cellulite at the University Hospital of Butare (Rwanda). Odonstostomatolofy Too Much, 19, 16-20.

[8] Seppanen, L., Rautemaa, R., Lindqvist, C. and Lauhio, A. (2010) Changing Clinical 
Features of Odontogenic Maxillofacial Infections. Clinical Oral Investigations, 14, 459-465. https://doi.org/10.1007/s00784-009-0281-5

[9] Gérard, N.B. (2006) Diffuse Cervico-Facial Cellulitis of Dental Origin. Thesis Memory, University of Cocody Abidjan, Abidjan, 73.

[10] Rouadi, S., Ouaissi, L., Khiadi, El.R., et al. (2013) Cervico-Facial Cellulitis about 130 Cases. Pan African Medical Journal, 14, 88. https://doi.org/10.11604/pamj.2013.14.88.1477

[11] Aswan, C., Anzouan, K., Aka-Aduko, J.A., Millogo, M., Nguessan, N., Diomande, A., et al. (2012) Management of Cellulite in Diabetics. International Journal of the African College of Odontostomatology and Maxillo-Facial Surgery, 19, 16-19.

[12] Hounkpe, Y.Y.C., Oussa, G.B., Vodouhe, S.J., Babagbet, M.J., Medji, A.L.P. and Bassabi, S.K. (1990) Cervicofacial Cellulitis. About 55 Cases Collected in the Services of Orl and Ophthalmology CNHU Cotonou. Black African Medicine, 37, 29-34.

[13] Rakotoarison, R.A., Ramarozatovo, N.P., Rakoto, F.A. and Rakotovao, F.J. (2008) Cervico-Facial Cellulitis: About 41 Cases. Journal of Oral Medicine and Oral Surgery, 14, 35-39.

[14] Potard, G. (2000) Cellulitis of the Face and Neck. Official Journal of the French Society of ORL and Cervico-Facial Surgery, 64, 11-26.

[15] Doumbia-Singare, K., Timbo, S.K., Keita, M., Aq Mohamed, A., Guindo, B. and Soumaoro, S. (2014) Cervico-Facial Cellulitis during Pregnancy; about a Series of 10 Boxes in Mali. Bulletin de la Société de Pathologie Exotique, 107, 312-316. https://doi.org/10.1007/s13149-014-0401-6

[16] Diallo, O.R., Balden, M., Conde, B., Camara, S. and Bah, A.T. (2006) Cervico-Facial Cellulitis in the Diabetic Patient at Conakry University Hospital. International Journal of the African College of Odontostomatology and Maxillo-Facial Surgery, 13, 13-16.

[17] Kpemissi, E. (1995) Cervico-Facial Cellulitis of Oral Origin: Study of 26 Cases at Lomé University Hospital. Journal of Laryngology, Otology and Rhinology, 116, 195-197.

[18] Benzarti, S., Mardassi, A., Benmhamed, R., Hachicha, A., Brahem, H., Hakkari, K., Miled, I. and Chebbi, M.K. (2007) Cervico-Facial Cellulitis of Dental Origin about 150 Cases. Tunisian ORL Journal, 19, 24-28.

[19] Mateo, J., Petipas, F. and Payen, D. (2006) Necrotizing Bacterial Dermohypodermatitis and Necrotizing Fasciitis. ENT Cellulitis French Annals of Anesthesia and Resuscitation, 25, 975-977. https://doi.org/10.1016/j.annfar.2006.03.019

[20] Wong, T.-Y., et al. (2000) Cervical Necrotizing Fasciitis of Odontqgenic Origin Report of 11 Cases. Journal of Oral and Maxillofacial Surgery, 58, 1347-1352. https://doi.org/10.1053/joms.2000.18259

[21] Tran Ban Huy, P. and Manach, Y. (2002) ENT Emergencies, Report 2002, French Company of Otorhinolaryngology and Surgery of the Face and Neck.

[22] Benariba, F., Ammar, H. and Alouane, M. (2007) Cervico-Facial Cellulitis. About 5 Cases. Medicine and Armies, 35, 171-178.

[23] Razafindrabe, J.A.B., Ramdrimanatenasoa, V.H., Andrianasolo, M.F., Radaviarison, M.F., Rasoarimasy, V.O. and Rakotovao, J.D. (2007) Epidemiological and Clinical Aspect of Dental Cellulitis in Antananarivo. The American Journal of the Medical Sciences, 7, 1108-1111. https://doi.org/10.3923/jms.2007.1108.1111

[24] Ennuri, A., Bouzouita, N., Hajri, H., et al. (1991) Cervico-Facial Cellulitis about 20 
Cases. Medical Tunisia, 69, 459-462.

[25] Romain, Schmidt, P., Hannion, X., et al. (1989) Cervico-Facial Gangrenous Cellulitis of Dental Origin: About 11 Cases. Revue de Stomatologie et de Chirurgie Maxillo-Faciale, 6, 428-437. 